\title{
CURSOS DE FORMAÇÃO DE PROFISSIONAIS DE EDUCAÇÃO MAL AVALIADOS E IMPACTOS NO DESEMPENHO ESTUDANTIL EM TESTES DE LARGA ESCALA
}

\author{
CURSOS DE FORMACIÓN DEL PROFESIONALES DE EDUCACIÓN DE BAJA \\ CALIFICACIÓN PARA PROFESIONALES DE LA EDUCACIÓN E IMPACTOS EN EL \\ RENDIMIENTO DE LOS ESTUDIANTES EN PRUEBAS A GRAN ESCALA
}

\author{
POORLY RATED HIGHER EDUCATION COURSES FOR EDUCATION \\ PROFESSIONALS AND IMPACTS ON STUDENT PERFORMANCE IN LARGE- \\ SCALE TESTS
}

RESUMO: Afirmando haver relação entre a qualidade da formação dos profissionais de educação e o desempenho de estudantes de 15 anos em testes internacionais de larga escala, a investigação tomou como ferramenta de busca os cursos de Matemática, Biologia e Pedagogia/Letras existentes no Brasil avaliados pelo RUF 2019 - Ranking Universitário Folha e os dados do relatório do PISA (Programa Internacional de Avaliação de Estudantes) a fim de comprová-la. Também se observou que as normas legais que deveriam orientar o perfil do profissional de educação e a estruturação curricular dos cursos de formação têm sido erráticas, dificultando que se consolidem e possam ser avaliados. Ao comparar os cursos existentes com a amostra construída pelo PISA para a aplicação dos testes, foi percebida a simetria entre profissionais de educação egressos de cursos mal avaliados e baixos desempenhos dos estudantes, assim como a necessidade de políticas garantidoras da qualidade dos cursos de formação, uma condição para diminuir as desigualdades regionais características da sociedade brasileira.

PALAVRAS-CHAVE: Ensino superior. Formação de Professores. Cursos superiores de formação. Avaliação.

RESUMEN: Afirmando que existe una relación entre la calidad de la formación de los profesionales de la educación y el desempeño de los estudiantes de 15 años en los exámenes internacionales de gran escala, la investigación tomó como herramienta de investigación la clasificación de los cursos de Matemática, Biología y Pedagogía / Literatura existente en Brasil realizado por RUF 2019 - Ranking Folha Universitaria y PISA - Programa de Evaluación de Estudiantes Internacionales - para probar esta afirmación. También se observó que las normas legales que deben orientar el perfil de los profesionales de la educación y la estructura curricular de los cursos de formación han sido equivocadas, dificultando su consolidación y evaluación. Al comparar los cursos existentes con la muestra construida por PISA para la aplicación de las pruebas se notó la simetría entre los

${ }^{1}$ Universidade do Estado do Rio de Janeiro (UERJ), Rio de Janeiro - RJ - Brasil. Professor Titular da Faculdade de Educação, Departamento de Políticas Públicas, Avaliação e Gestão da Educação (DEPAG). Coordenador do Programa de Pós-Graduação em Desenvolvimento e Educação Teotonio dos Santos (ProDEd-TS). Doutorado em Educação (UFRJ). ORCID: https://orcid.org/0000-0002-8279-9340. E-mail: zacarias_gama@yahoo.com.br 
profesionales de la educación egresados de cursos mal evaluados y el bajo desempeño de los estudiantes, asi como la necesidad de políticas que garanticen la Calidad de los estudiantes Cursos de formación, condición para reducir las desigualdades regionales propias de la sociedad brasileña.

PALABRAS CLAVE: Educación superior. Formación docente. Cursos de educación superior. Evaluación.

ABSTRACT: Affirming to exist relationship between the quality of the formation of education professionals and the performance of 15-year-old students in large-scale international tests, the investigation took as search tool the classification of existing Mathematics, Biology and Pedagogy/Letters courses in Brazil carried out by RUF 2019 Folha University Ranking and PISA - Programme for International Student Assessment - to prove this affirmation. It was also observed that the legal rules that should guide the profile of the education professional and the curricular structure of formation courses have been erratic, making it difficult their consolidation and evaluation. When comparing the existing courses with the sample built by PISA for the application of the tests, it was noticed the symmetry between education professionals egressed from poorly evaluated courses and low performance of the students, as well as the need for policies that guarantee the quality of the formation courses, a condition to reduce the regional inequalities characteristic of Brazilian society.

KEYWORDS: Higher education. Teacher education. Higher education courses. Evaluation.

\section{Introdução}

São inúmeras as investigações sobre o fracasso educacional brasileiro e elas não se furtam a apresentar resultados que contribuem para tornar as políticas públicas mais eficientes e melhorar a qualidade da educação. É consensual que a desigualdade social que situa o Brasil entre os países com as piores distribuições de renda se encontra na raiz do problema, muito embora não seja a razão suficiente. Há muito ainda que investigar. No presente texto, a formação de profissionais de educação será tomada como objeto de análise, com o objetivo de localizar geograficamente as melhores instituições públicas e particulares. Duas hipóteses orientam o seu desenvolvimento. A primeira: as orientações legais para a formação de profissionais de educação têm uma concepção técnica atual compatível com a de ministradores de conteúdo sem visão de totalidade social, isto é, profissionais que transformam o conteúdo de sua disciplina em coisa em si, incapaz de ser compreendida para além de si mesma e praticamente sem relações com as demais disciplinas do currículo escolar. A segunda: a desigualdade socioeconômica característica da sociedade brasileira se reproduz no campo educacional a partir da desigual distribuição dos cursos de formação de boa 
qualidade e, consequentemente, do confinamento de profissionais de educação formados por cursos mal avaliados nas periferias das grandes cidades.

A fim de checar ambas as hipóteses, tomarei como objeto as resoluções do Conselho Nacional de Educação, de 2006 até o presente, e dados do Ranking Universitário Folha $(\mathrm{RUF})^{2}$, INEP/MEC e do PISA/OCDE $(2018)^{3}$.

\section{A concepção de profissionais de educação e as orientações oficiais para sua formação}

Tem sido corrente, desde os anos 1980, designar o professor como trabalhador ou profissional de educação. Tal como em uma figura de linguagem passou-se a usar a designação profissional de educação sem se questionar as razões que a justificaram, dada a relação objetiva que havia entre os dois termos, trabalhador e professor. O termo profissional de educação foi empregado como estratégia político-sindical para aumentar o quantitativo e a força da categoria, agregando-lhe os administradores, supervisores, inspetores, orientadores e demais funcionários técnico-administrativos. No estado do Rio de Janeiro, a partir de 1987, o Centro Estadual dos Profissionais de Educação (atual SEPE-RJ) realizou esta inclusão. Era um tempo em que a presença sindical na vida brasileira se fazia forte, assim como também as novas lideranças (RODRIGUES, 1992). A profissionalização se opunha à grande presença de leigos e à proletarização e, ao mesmo tempo, preservava a autonomia docente, privilégios e vagas no mercado de trabalho, como Enguita (1991) observou em seus estudos.

A LDB de 1996 ratificou o termo e trouxe como novidade em seus artigos 61 e 62 a definição de profissional de educação escolar básica: aquele que possui habilitação de nível médio ou superior, diploma de pedagogia, mestrado ou doutorado na área de atuação; diplomas de cursos técnicos em área pedagógica; notório saber; complementação pedagógica; e sólida formação básica, capacidade de associar teoria e prática e experiências no campo educacional. Mas, como se pode observar, ambos artigos são essencialmente formais, eles definem quem pode assumir turmas e qual deve ser a sua formação essencial, e deixam a definição dos conteúdos formativos para futuras resoluções do Conselho Nacional de

${ }^{2} \mathrm{O}$ RUF ranqueia anualmente as instituições de ensino superior presenciais e a distância existentes no Brasil. Ele é produzido pelo Jornal Folha de São Paulo. A escala de classificação utilizada vai de 0 a 100 e, como se poderá observar, as melhores IES brasileiras sequer chegam a 70 pontos. As melhores ficam no intervalo 55 - 65 pontos. Assim, ao considerar as melhores tenho clareza da posição que podem ocupar em rankings internacionais. Em nenhum deles seriam sequer incluídas no Top 100. No ranking organizado pela QS World University Rankings as melhores universidades brasileiras - USP, UNICAMP e UFRJ - foram respectivamente colocadas em $118^{\circ}, 204^{\circ}$ e $361^{\circ}$ lugares.

${ }^{3}$ OCDE. Programme for international student assessment (PISA) - Results from PISA 2018. Disponível em: https://www.oecd.org/pisa/publications/PISA2018_CN_BRA.pdf. Acesso em: 10 maio 2020. 
Educação. A Lei $N^{o} 13.054$, de 22 de dezembro de 2014, por fim, consagrou o termo e instituiu o dia 6 de agosto como o Dia Nacional dos Profissionais da Educação, extinguindo o Decreto $\mathrm{n}^{\circ} 52.682$, de 14 de outubro de 1963, que declarava o dia 15 de outubro como o Dia do Professor. Não obstante toda esta trajetória, do meu ponto de vista, é imperativo discutir com profundidade os dois termos: professores e profissionais de educação. A conjuntura nacional mudou e seria adequado um balanço dos avanços e recuos. Mas, a prevalecer o termo profissional de educação, qual deve, afinal, ser a sua formação?

Até o presente, uma coisa parece certa, ainda estamos à espera do consenso a respeito, até mesmo no âmbito do Conselho Nacional de Educação (CNE) que, desde o início dos anos 2000, já editou diversas deliberações tentando definir a formação adequada em sucessivas idas e vindas. O movimento errático existente caracteriza, no entanto, o que há muito Cunha definiu como políticas de ziguezague incapazes de resistir ao personalismo dos grupos que se hegemonizam na Câmara de Educação Superior a cada período, os quais alteram substantivamente o teor da formação do profissional de educação (CUNHA, 2006).

A Resolução CNE/CP N $\mathrm{N}^{\mathrm{1}}$, de 15 de maio de 2006, que instituiu as Diretrizes Curriculares Nacionais para os cursos de graduação, orientou as IES a incentivar uma formação geral sólida, bem como a autonomia profissional e intelectual com reconhecidos conhecimentos, competências e habilidades adquiridos dentro e fora do ambiente escolar, e com capacidade de articular teoria e práticas individuais e coletivas de pesquisa. Tais conhecimentos deveriam derivar da articulação entre "conhecimentos científicos e culturais, valores éticos e estéticos inerentes a processos de aprendizagem, de socialização e de construção do conhecimento, no âmbito do diálogo entre diferentes visões de mundo". As IES garantiriam uma formatividade na qual teria centralidade o equilíbrio entre estudos teóricos e empíricos e a lida com a ciência, ética e estética sem se fechar com exclusividade em um mundo particular. Seria uma formação lato sensu, abrangendo "a filosofia, a história, a antropologia, o ambiental-ecológico, o psicológico, o linguístico, o sociológico, o político, o econômico, o cultural", bem como o conhecimento da escola como organização complexa, capacidade de aplicar resultados de investigações, participar da gestão de processos educativos e da organização e funcionamento de sistemas e instituições de ensino.

A despeito das dificuldades das IES, sobretudo das IES públicas, de implantar corretamente as alterações curriculares, muito em função da existência de inúmeros conselhos e colegiados, e sem avaliações recomendáveis da operacionalidade e do perfil dos formados, o CNE editou uma nova Resolução, a de $n^{\circ} 2$, de $1^{\circ}$ de julho de 2015 . Ela introduziu o princípio da formação continuada objetivando levar o profissional de educação a refletir sobre a sua 
prática e a apurar a sua formação técnica, pedagógica, ética e política em atividades de extensão, grupos de estudos, reuniões pedagógicas, cursos, programa e outras ações para além da formação mínima. Esta formação, bem ao gosto dos empresários de educação, por razões óbvias, não seria necessariamente oferecida e/ou subsidiada pelo Estado no escopo de uma política bem estruturada; o Estado apenas garantiria o "respeito ao protagonismo do professor e [o direito] a um espaço-tempo que lhe permita refletir criticamente e aperfeiçoar sua prática" (Art. 16, III). A compreensão do professor como protagonista é um notável avanço, muito embora tenha deixado de ser acompanhada da proposição de eficiente política para a sua realização, que evitasse dispersões formativas, ônus para o profissional de educação, e criasse condições objetivas para que pudesse aprofundar os seus estudos com, por exemplo, facilitação de licenças, bolsas de estudo e manutenção dos seus vencimentos. Os princípios de formatividade contidos na Resolução anterior continuaram presentes, bem como o equilíbrio entre estudos teóricos e empíricos e a lida com a ciência/pesquisa, ética e estética.

$\mathrm{Na}$ Resolução $\mathrm{n}^{\mathrm{o}}$ 2, de $1^{\mathrm{o}}$ de julho de 2015 é preciso atentar para o caráter multifuncional ou polivalente atribuído ao profissional de educação como docente, pesquisador, gestor etc., bem de acordo com a doutrina neoliberal. Ela lhe adjudica várias atividades não necessariamente de natureza docente, de forma a economizar na organização e no funcionamento escolar. Essa multifuncionalidade, visível na intersecção de dois ou mais postos de trabalho quaisquer no interior das escolas, se por um lado atende aos gestores fazendários, por outro compromete a existência de um magistério de qualidade porque restringe a profundidade da formação, ação docente e os graus de autonomia indispensáveis. É uma contradição pretender que o profissional de educação seja, ao mesmo tempo, professor e gestor. Esta multifuncionalidade que se impõe ao profisssional de educação não é apenas técnico-econômica, ela também se apresenta involucrada de elementos políticos, ideológicos e psicológicos próprios da doutrina neoliberal que engendram a transição das escolas como instituições sociais, garantidoras dos direitos à educação inscritos na Constituição Federal, para o status de organização escolar, o que as insere no setor de serviços não exclusivos do Estado e a reduzem ao mesmo status de outras organizações sociais ${ }^{4}$.

A Resolução CNE/CP n ${ }^{\circ}$ 2, de 20 de dezembro de 2019, transparece com muita nitidez diversos aspectos do atual governo neofascista e antidemocrático do presidente Jair M. Bolsonaro, em especial, as restrições ao ato de educar de forma a evitar que, como disse

4 Para maior aprofundamento ver CHAUÍ, M. A universidade operacional. Disponível em: https://www2.unifap.br/borges/files/2011/02/A-Universidade-Operacional-Marilena-Chau\%C3\%AD.pdf. Acesso em: 10 jun. 2020. 
Frigotto (2017, p. 31), “seja um confronto de visões de mundo, de concepções científicas e de métodos pedagógicos, desenvolver a capacidade de ler criticamente a realidade e constituírem-se sujeitos autônomos". A grande expectativa é que a formatividade do profissional de educação fique subordinada aos conteúdos próprios de sua ação docente, nada mais que isto. Tal Resolução estabelece ainda que os currículos dos cursos de formação sejam referenciados pela Base Nacional Comum Curricular (BNCC-Educação Básica) e que as IES tenham dois anos para implementá-los. Resolve que o profissional de educação deve ter as seguintes competências: conhecimento, prática e engajamento profissional. Mais especificamente, deve saber planejar as ações de ensino; avaliar o desenvolvimento do educando; a aprendizagem e o ensino; e conduzir as práticas pedagógicas dos objetos do conhecimento, competências e as habilidades. Deverá ainda ser um profissional engajado com o seu desenvolvimento, aprendizagem dos estudantes, projeto pedagógico da escola, valores democráticos, famílias e comunidade escolar. Não mais se pretende o seu envolvimento direto na gestão administrativa da escola; quando muito, que tenha noções sobre a governança dos sistemas educacionais. Revela-se, contudo, omissa quanto à formação específica dos administradores escolares e nada altera quanto à formação continuada; ela persiste e se mantém como reponsabilidade e ônus do profissional de educação e conforme as suas demandas subjetivas; o vazio de políticas que a possam orientar prossegue, assim como nada acrescenta em termos de subsídios e facilidade de liberação remunerada de carga horária.

O crônico zigue-zague dificulta a concretização do consenso necessário à definição do profissional de educação no Brasil; diversos estudos das ciências da educação demonstram os malefícios dos movimentos erráticos promovidos pelas autoridades educacionais. Em três gestões governamentais, no curto espaço de cinco anos, três resoluções do Conselho Nacional de Educação organizaram e desorganizaram os cursos de formação. Se temos em mente a quantidade de instituições com oferecimento de cursos de formação espalhadas pelo território nacional e os impactos que tais preceitos legais lhes impõe, fica fácil imaginar os descompassos e os efeitos colaterais desse zigue-zague.

Os profissionais de educação, segundo esta última Resolução, ficam reduzidos a ministradores de conteúdo sem visão de totalidade social e que transformam o conteúdo de suas disciplinas em coisas si, incapazes de serem compreendidas para além de si mesmas e praticamente sem relações com as demais disciplinas do currículo escolar. Ao atual governo interessa a existência de profissionais que atuem mais como instrutores e nada como educadores em sentido lato. $\mathrm{O}$ documento legal vigente restringe os limites de atuação docente em consonância com a proposta Escola Sem Partido, a qual, se aprovada, dissociaria 
"o ato de educar e o ato de instruir. $\mathrm{O}$ ato de educar seria responsabilidade da família e da religião; o professor se limitaria a instruir, o que equivaleria a transmitir conhecimento neutro, sem mobilizar valores e sem discutir" (PENNA, 2017, p. 36).

\section{Os cursos de formação de profissionais de educação}

Nos cursos de formação de profissionais de educação oferecidos por IES públicas e particulares espalhadas pelo território brasileiro estão matriculados 8,5 milhões de estudantes em 7.415 cursos presenciais e a distância, de todas as áreas e carreiras, dos quais 3.785 são públicas e 3.630 privadas (INEP, 2018). A maioria de concluintes em 2018 (250.453) estava matriculada em instituições privadas, 173.274. Esta é a realidade concreta do Brasil e o ponto de partida da análise que proponho, entendendo, entretanto, que esta realidade empírica pouco ou nada nos diz sobre a qualidade dos cursos nem a respeito dos profissionais que forma.

Dada a extensão e heterogeneidade desta realidade, é imperativo que me atenha aos cursos presenciais e a distância cujos conteúdos são avaliados pelo PISA, isto é, os cursos de Biologia (Ciências), Matemática e Pedagogia/Letras (Letramento em Leitura). O que justifica tal recorte é o desempenho pífio dos estudantes brasileiros em comparação à média dos demais estudantes dos 70 países participantes. Os dados do RUF 2019 - Ranking Universitário Folha possibilitarão tal análise.

O RUF avalia e classifica em uma escala de 0.0 a 100 todos os cursos presenciais de graduação das universidades, centros universitários e faculdades, públicos e particulares, tendo como critérios: Ensino/Pesquisa e Inserção dos egressos no mercado de trabalho.

\section{Cursos de Biologia (Ciências)}

São oferecidos 379 cursos presenciais de Biologia (Ciências): 143 nas IES públicas (universidades, centros universitários, faculdades, institutos superiores e CEFET) e 234 nas IES privadas. As cinco primeiras IES colocadas no ranking de melhores cursos de Biologia são todas públicas: USP, UNICAMP, UFRJ, UFMG, UNESP; suas pontuações, pela ordem, oscilam entre 62,92 e 55,73 pontos em ensino. As IES particulares, mais bem situadas no mesmo ranking, são: PUC-RS, PUC-PR, MACKENZIE, UNESP, PUC-MG, com pontuações em ensino bem abaixo das IES públicas; pela ordem as pontuações decrescem de 43,83 a 14,18 . 
Observa-se de imediato a menor pontuação das IES privadas na avaliação de Ensino. A diferença de pontos entre para as IES públicas primeiras colocadas põe em evidência a fragilidade das IES privadas na oferta do ensino de Biologia; a distância entre elas se torna mais escandalosa ao se comparar a diferença de 21,09 pontos entre a USP e a PUC-RS, esta última a melhor IES particular.

As IES públicas e particulares mais mal situadas no mesmo ranking têm acentuadas diferenças em termos de ensino. Exatamente 121 IES públicas, 34,47\%, mais de um terço do total, sequer conseguem obter metade dos pontos da USP, e 77 delas, isto é, 21,9\%, sequer são referenciadas. Entre as 234 IES privadas, apenas as duas mais bem colocadas no RUF 2019 têm pontuação acima da metade dos pontos obtidos pelas melhores IES públicas. As demais IES privadas - 99,14\% delas - sequer conseguem obter 20.00 pontos.

A dispersão de IES públicas e particulares pelo território brasileiro reflete as desigualdades entre as unidades federativas ricas e pobres na oferta de cursos de formação de profissionais de Biologia. Os melhores e mais bem avaliados cursos estão localizados nas unidades federativas mais ricas: Bahia, Distrito Federal, Goiás, Minas Gerais, Pernambuco, Rio de Janeiro, Rio Grande do Sul, Santa Catarina e São Paulo. Fora das capitais podem ser encontrados em Feira de Santana (BA), Viçosa e Uberlândia (MG), Seropédica e Campos dos Goytacazes (RJ), Santa Maria e Pelotas (RS), Campinas e São Carlos (SP). Os demais estados: Acre, Alagoas, Amapá, Amazonas, Ceará, Espírito Santo, Maranhão, Mato Grosso, Mato Grosso do Sul, Pará, Paraíba, Piauí, Rio Grande do Norte, Roraima, Rondônia, Sergipe e Tocantins oferecem cursos com avaliação abaixo da média das cinco IES públicas mais bem colocadas no RUF 2019. Isto quer dizer que $67,7 \%$ das unidades federativas oferecem cursos mal avaliados e contribuem fortemente para confinar no interior os profissionais de Biologia, eles que atendem a $49 \%$ da população interiorana, tanto nas áreas urbanas, 74\%, como nas áreas rurais, $26 \%(\mathrm{DATASEBRAE},[\mathrm{s} / \mathrm{d}])^{5}$.

\section{Cursos de Matemática}

As IES que oferecem o melhor ensino em Matemática no Brasil, total de 143, são todas públicas, como se observa no quadro abaixo: USP, UNICAMP, UFRJ, UFMG e UFRGS, com pontuação, pela ordem, entre 62.4 e 57.12. As IES privadas que estão no topo do ranking são: PUC-RIO, MACKENZIE, PUC-PR, UNIP, PUC-RS, com uma pontuação

5 DATASEBRAE. População do interior. Disponível em: https://datasebrae.com.br/populacao-dointerior/\#moradores. Acesso em: 10 jun. 2020.

RIAEE - Revista Ibero-Americana de Estudos em Educação, Araraquara, v. 16, n. 4, p. 2427-2442, out./dez. 2021. e-ISSN: 1982-5587 
entre 34,38 e 27,57 . As IES públicas que se situam na base do mesmo ranking estão longe de conseguir 5.00 pontos em avaliação do ensino. Nos 140 cursos das IES Privadas a situação em termos de ensino é exatamente igual. Entre 143 cursos de Matemática privados, 97.14\% são incapazes de alcançar 20.00 pontos em qualidade de ensino.

A dispersão de IES públicas e particulares que oferecem cursos de Matemática no território deixa transparecer de forma ainda mais eloquente as desigualdades regionais. Os melhores e mais bem avaliados cursos, acima de 50.00 pontos, todos estão localizados nos estados mais ricos: Rio Grande do Sul e Santa Catarina, na Região Sul; São Paulo, Minas Gerais e Rio de Janeiro na Região Sudeste; e no Distrito Federal. Os únicos cursos com pontos iguais ou acima desta média no interior encontram-se nas cidades de Campinas, $\mathrm{ABC}$ e São Carlos em São Paulo, Londrina e Maringá no Paraná, Santa Maria no Rio Grande do Sul, e Niterói no Rio de Janeiro. Na maioria das unidades federativas - 77,8\% - é possível encontrar cursos de Matemática com baixíssima qualidade.

\section{Cursos de Pedagogia}

O profissional de educação licenciado em Pedagogia tem grande importância no desenvolvimento cognitivo das crianças, na medida em que atende aos anos iniciais do ensino fundamental, isto é, a crianças de seis a dez anos. São nestes anos iniciais que as crianças são "alfabetizadas", quer dizer, são iniciadas no domínio da língua falada e escrita, nos princípios matemáticos, e adquire noções de espaço, tempo, ciências, artes e estética. Para a OCDE, que aplica os exames do PISA, elas estão em fase de letramento em leitura, matemática e ciências. A definição de letramento em leitura que esta organização utiliza é a seguinte: "O letramento em Leitura refere-se a compreender, usar, refletir sobre textos escritos, a fim de alcançar um objetivo, desenvolver seu conhecimento e seu potencial, e participar da sociedade." (INEP/MEC, 2019).

Nos exames de letramento em leitura a média de desempenho dos estudantes brasileiros é de 413 pontos, 74 pontos abaixo da média dos demais estudantes participantes no PISA 2018. No ranking, a pontuação do Brasil o situou no seguinte intervalo: 55-59 pontos, atrás do Chile, Uruguai, Costa Rica e México.

No Brasil há 144 IES públicas que oferecem o Curso de Pedagogia. As mais bem colocadas no RUF 2019 são: UFMG, UFRJ, UNESP, USP, UNICAMP, cujas pontuações oscilam entre 61.74 e 54.88. Os mais bem avaliados são oferecidos pelas seguintes IES Privadas: PUC-SP, PUC-RIO, MACKENZIE, UNISINOS, PUC-RS, com pontuação que 
oscila entre 57.17 e 46.71 . Estas cinco melhores IES privadas ainda assim ficam abaixo da média das cinco melhores IES públicas e laicas. As demais IES privadas, 913 no total, decepcionam em termos de formação do profissional de educação licenciado em Pedagogia. Cerca de $87.52 \%$ delas sequer atingem a metade da média das cinco melhores IES públicas.

Quando se analisa o universo das IES particulares, com oferecimento do Curso de Pedagogia, chama a atenção a concentração delas em alguns estados: São Paulo é o campeão, com 268, seguido de Minas Gerais, 102; Paraná, 80; e Bahia, 56. Bourdieu, acerca de tamanha profusão de cursos e hiperinflação de diplomas, diria que ela responde à demanda de muitos indivíduos e grupos, na medida em que sonham ocupar postos na hierarquia funcional, mesmo que o nível do diploma seja desvalorizado e barateada a remuneração compatível (BOURDIEU apud HEY; CATANI; MEDEIROS, 2018). Para os empresários da educação é um negócio da China ofertar cursos baratos para pessoas pouco interessadas em elevados investimentos de estudos, concentração e tempo.

Apenas três estados entre os mais ricos, dois da Região Sudeste - Minas Gerais e São Paulo - e um da Região Sul - Rio Grande do Sul, oferecem Cursos de Pedagogia bem avaliados. Todos os demais sequer atingem a média de 58.17 pontos obtida pelas cinco melhores IES Públicas.

\section{Cursos de Letras}

O letramento em leitura, próprio dos anos iniciais do ensino fundamental, alarga os horizontes dos estudantes quando estes passam a ter contato com a disciplina Língua Portuguesa, cujo magistério é exclusivo dos estudantes licenciados em Letras. É isto o que justifica identificar a qualidade de ensino de Letras ofertada pelas muitas IES públicas e privadas. De acordo com o RUF 2019 existem 413 IES públicas e particulares que o oferecem, mais precisamente 129 IES públicas e 283 IES privadas. As IES públicas e privadas que oferecem cursos mais bem avaliados são: USP, UNICAMP, UFMG, UFRJ e UFF, com pontuação variando entre 62.25 e 53.67. As IES privadas são: PUC-SP, PUC-RS, PUC-MG, MACKENZIE e UNISINOS. Todas elas com pontos abaixo das IES públicas; as pontuações variam de 50.54 a 16.23 em qualidade de ensino.

Semelhante ao que foi visto na oferta dos cursos de Pedagogia, os cursos de Letras das IES privadas e religiosas se destacam entre os melhores. Mesmo assim, a avaliação de todas em qualidade de Ensino fica bem abaixo da média das IES Públicas. Aliás, 279 IES privadas sequer conseguem 17.00 pontos de avaliação, e isto corresponde a 98,58\% do total. 
No universo dos cursos de Letras, as desigualdades entre as unidades da Federação se revelam ainda maiores. Somente quatro unidades da Federação têm cursos bem avaliados: São Paulo, Rio de Janeiro, Minas Gerais e Distrito Federal. A quantidade de cursos mal avaliados das IES privadas segue a lógica da desigualdade, concentrando-se também nos estados mais ricos, onde o poder aquisitivo da população é maior.

As observações que faço, as quais me elevam do abstrato mundo das IES públicas e particulares, apresentado em quantidades no início desta seção, permitiram-me chegar concretamente a uma realidade preocupante. A concentração dos cursos mais avaliados nos estados mais ricos e desenvolvidos da Federação torna visível o quão distante de ser democratizada está a formação de profissionais de educação. A maioria oferece cursos com baixa qualidade de ensino. A profusão de cursos de Pedagogia que podem ser considerados ruins chega a ser escandalosa, e se torna imperativo a criação de meios eficientes de fiscalização e punição, porquanto são vendidos enganosamente. Tal profusão, entretanto, que não é exclusiva ao oferecimento de formação em Pedagogia, e acaba por criar um círculo distante de ser virtuoso e que precisa ser rompido: profissionais de educação mal formados oferecem ensino de baixa qualidade a estudantes da educação básica que, futuramente, tornam-se docentes em cursos de má qualidade de ensino.

\section{PISA x Cursos de Formação de Profissionais de Educação}

O PISA, exame aplicado pela OCDE, avalia trienalmente o desempenho dos estudantes em Matemática, Letramento em Leitura e Ciências desde o ano 2000, buscando saber: “o que é importante que os cidadãos saibam e sejam capazes de fazer?". Mais especificamente, que conhecimentos e habilidades essenciais os estudantes de 15 anos de idade já dominam. E faz isto com base na Teoria do Capital Humano, acreditando que as economias modernas se desenvolvem e "recompensam os indivíduos não apenas pelo que sabem, mas cada vez mais pelo que conseguem fazer com o que sabem" (INEP/MEC, 2019).

A amostra de participantes dos exames abrange 10.691 estudantes do meio urbano (10.271) e rural (420), capitais (2.462) e cidades do interior (8.229). Desde 2006, o Brasil submete a exames estudantes de 661 escolas distribuídas pelas regiões geográficas com níveis amostrais de precisão aceitáveis, excetuando-se as escolas indígenas, rurais da região Norte, de assentamentos, comunidades quilombolas e unidades de conservação sustentável. Os resultados por região estão no gráfico abaixo, observando-se desde já a relação direta entre 
cursos de formação de profissionais de educação com baixa avaliação e o menor desempenho dos estudantes.

Figura 1 - Relatório Brasil no PISA 2018 - Versão preliminar

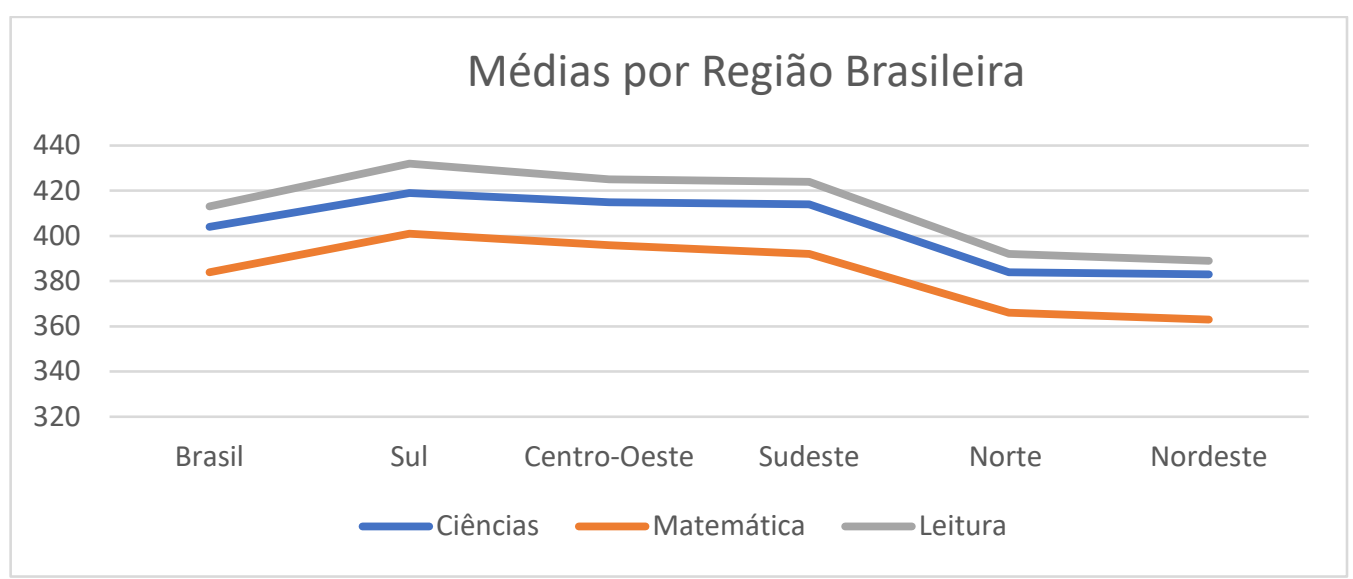

Fonte: INEP/MEC (2019)

Como se observa no gráfico, são maiores as médias obtidas pelos estudantes nas regiões mais ricas do país, onde estão concentrados os cursos de formação mais bem avaliados. É recorrente a análise de desempenho tendo como objeto os conhecimentos e habilidades expressos pelos estudantes, considerando suas motivações e o contexto em que vivem: região, dependência administrativa, ambiente escolar (práticas de ensino, oportunidades de aprendizagem, políticas escolares), localização das escolas e nível socioeconômico. O estudante é o elemento central. São raríssimos os estudos que estabelecem relações entre a qualidade dos cursos de formação docente e os desempenhos dos estudantes.

O relatório final produzido pela OCDE é minucioso e cuidadoso ao caracterizar o ambiente escolar, estabelecer relações entre o nível socioeconômico e o desempenho dos estudantes, disponibilidade ou adequação da infraestrutura e os recursos escolares. Seu ponto de partida é um constructo prévio para balizar quem se enveredar no complexo e desigual campo educacional brasileiro. Em uma linguagem weberiana poder-se-ia chamar tal constructo de tipo ideal, que supõe um ponto médio e as adequações acima e abaixo. O que foi avaliado pelo PISA foi predefinido a priori e corresponde a aspectos julgados importantes, baseando-se nos valores que lhes são caros. Talvez por esta razão se supõe que os livros didáticos coloquem desafios aos estudantes e os profissionais de educação tenham formação adequada, a despeito de os diretores de escolas rurais com "elevado percentual de estudantes [sempre considerarem], entretanto, que a indisponibilidade ou inadequação da infraestrutura e dos recursos escolares afetam muito ou até certo ponto o processo de aprendizagem" 
(INEP/MEC, 2019, p. 145). Este constructo é fator de inteligibilidade; na pesquisa é guia importante para a elaboração das hipóteses e na exposição, como Moraes, Del Maestro Filho e Dias (2003, p. 64) observaram, serve "para a descrição de meios de expressão unívocos e precisos”. A utilização de indicadores construídos abstratamente leva, todavia, a que o constructo menospreze aspectos qualitativos essenciais; não por acaso as vozes dos diretores de escolas rurais são levadas em consideração apenas para efeito de registro, como uma deferência.

Em nenhum momento a qualidade da formação dos profissionais de educação é objeto de avaliação pela OCDE e nem é devidamente analisada. De certa forma, parte-se da aceitação de que os profissionais de educação são mais ou menos adequados, assim como os recursos didáticos. No entanto, quando colocamos vis-à-vis a amostra de estudantes construída para a aplicação dos testes com a distribuição dos cursos de formação de profissionais de educação pelo território brasileiro, assoma aos nossos olhos a relação direta e perversa que existe entre oferta de cursos de má qualidade de Matemática, Pedagogia/Letras e Ciências e os baixos desempenhos estudantis. Assim, como obter melhores desempenhos dos estudantes se os seus professores têm formação inadequada, se os conteúdos que ministram são fracos, se as suas explicações são precárias ou insuficientes? Como elevar os níveis de mediações dos estudantes com orientações e materiais didáticos insuficientes? A educação de qualidade referenciada socialmente que queremos e precisamos com urgência exige para a sua concretização ambientes escolares bem estruturados; recursos didáticos que possam contribuir para a elevação dos níveis reais e potenciais de conhecimento dos estudantes; e profissionais de educação bem qualificados. Nos testes do PISA, grande quantidade de estudantes omite respostas. No relatório final revela-se que os estudantes as omitem porque não sabem “integrar informação e fazer inferência”, mas será que os seus docentes sabem? Os estudantes e os docentes são capazes de fazer interpretações literais de resultados? Ambos conseguem “interpretar dados e evidências cientificamente: analisar e avaliar dados, afirmações e argumentos em uma variedade de representações, e tirar conclusões científicas apropriadas"? Se os docentes não sabem, como exigir que os estudantes saibam?

Os resultados desta investigação, como se pode constatar, são deveras preocupantes. A indefinição legal do perfil do profissional de educação e a má qualidade dos cursos de formação existentes têm impactos negativos nos desempenhos dos estudantes brasileiros. Estes resultados mostram, por sua vez, em que direções as políticas públicas precisam atuar com eficácia, assim como a necessidade de compromissos do Estado e da Sociedade com a formação de qualidade de nossos docentes. 


\section{À guisa de conclusões}

A minha análise a partir da realidade concreta, com a utilização de textos oficiais e utilização de dados obtidos junto ao INEP/MEC, RUF 2019, OCDE e outros, em síntese, trouxe à luz as múltiplas determinações às quais a formação do profissional de educação está sujeita. Determinações oficiais erráticas que dificultam definir qual docente e o desenvolvimento de todos os cursos oferecidos no território nacional, de todos os níveis e modalidades. Determinações provenientes dos modos como tais cursos se organizam: como instituições sociais públicas e sem fins lucrativos com o objetivo claro de garantir direitos consagrados constitucionalmente, e como organizações sociais privadas, nas quais o lucro individual é a primeira e única razão de existir. Em algumas instituições sociais mantidas pelos governos federal, estadual, distrital e municipal o ensino oferecido tem qualidade reconhecida socialmente, muito embora ainda precisem melhorar muito para chegar ao patamar das melhores IES internacionais. Na maioria das organizações sociais escolares, as IES privadas, com significativa exceção daquelas mantidas por instituições religiosas, predomina os cursos de baixíssima qualidade em Biologia, Matemática e Pedagogia/Letras.

As minhas duas hipóteses iniciais propiciaram razões para a investigação realizada e se comprovaram verdadeiras. As orientações legais para a formação do profissional de educação têm sido irregulares na definição de seu perfil e das competências necessárias, atualmente transformando-o em um ministrador de conteúdo sem visão de totalidade social, que trata os conteúdos de sua disciplina como coisa em si, e sem relação com os demais componentes curriculares. Os cursos ofertados estão dispersos no território brasileiro e refletem a desigualdade social que campeia. A maioria, de qualidade reprovável, praticamente confina os profissionais de educação aos seus lugares de pertencimento e às periferias das grandes cidades. Nas grandes metrópoles, principalmente das regiões Sul e Sudeste e no DF, assim como em algumas cidades do interior de São Paulo, Rio de Janeiro, Minas Gerais e Rio Grande do Sul, os melhores lugares de trabalho são ocupados pelos profissionais formados em cursos bem avaliados que existem nestes espaços.

A identificação da precariedade da maioria dos cursos públicos e privados de formação de profissionais de educação sugere a necessidade urgente de políticas públicas que cuidem da melhoria deles, como forma de democratizar a qualidade da formação docente. Como pôde ser observado, há relações diretas entre a má formação docente e o mal desempenho dos estudantes de 15 anos de idade, de todas as regiões do Brasil, nos exames do PISA. O nível real dos estudantes, desenvolvido na maioria das escolas urbanas e rurais de 
educação básica, não tem sido suficiente para elevar os seus potenciais de saber mais nas áreas de conhecimento que compõem os currículos escolares.

A elevação da qualidade da formação dos profissionais de educação é, pois, um imperativo categórico que se faz urgente. É impossível ter bons estudantes com profissionais de qualidade duvidosa. Garantir que todas as localidades de todas as regiões brasileiras tenham oferta de cursos de formação de professores de qualidade avaliada e referenciada socialmente, sem artifícios de propaganda, é uma exigência do processo de democratização do Brasil.

\section{REFERÊNCIAS}

CUNHA, L. A. Zigue-zague no Ministério da Educação: uma visão da educação superior. Rev. Contemp. de Edu., v. 1, n. 1, 2006.

ENGUITA, M. F. A ambiguidade da docência: entre o profissionalismo e a proletarização. Revista Teoria \& Educação, n. 4, 1991

FRIGOTTO, G. A gênese das teses do Escola sem Partido: esfinge e ovo da serpente que ameaçam a sociedade e a educação. In: FRIGOTTO, G. (org.) Escola "sem" partido: esfinge que ameaça a educação e a sociedade brasileira. Rio de Janeiro: UERJ, LPP, 2017.

HEY, A. P; CATANI, A. M; MEDEIROS, C. C. C. A sociologia da educação de Bourdieu na revista Actes de la Recherche en Sciences Sociales. Tempo Social, USP, v. 30, n. 2, 2018.

INEP. INSTITUTO NACIONAL DE ESTUDOS E PESQUISAS EDUCACIONAIS ANÍSIO TEIXEIRA. Sinopse Estatística da Educação Superior 2018. Brasília: Inep, 2019.

Disponível em http://portal.inep.gov.br/basica-censo-escolar-sinopse-sinopse. Acesso em: 10 jun. 2020.

INEP/MEC. Relatório Brasil no PISA 2018 - Versão preliminar. Brasília, DF: INEP/MEC 2019. Disponível no site:

http://download.inep.gov.br/acoes_internacionais/pisa/documentos/2019/relatorio_PISA_201 8 preliminar.pdf. Acesso em: 10 jun. 2020

MORAES, L. F. R; DEL MAESTRO FILHO, A; DIAS, D. V. O paradigma weberiano da ação social: um ensaio sobre a compreensão do sentido, a criação de tipos ideais e suas aplicações na teoria organizacional. Rev. adm. Contemp., Curitiba, v. 7, n. 2, p. 57-71, jun. 2003. Disponível em http://www.scielo.br/scielo.php?script=sci arttext\&pid=S1415$65552003000200004 \& \operatorname{lng}=$ pt\&nrm=iso. Acesso em: 10 jun. 2020.

PENNA, F. A. O Escola sem Partido como chave de leitura do fenômeno educacional. In: FRIGOTTO, G. (Org.) Escola "sem" partido: esfinge que ameaça a educação e a sociedade brasileira. Rio de Janeiro: UERJ, LPP, 2017.

RODRIGUES, L. M. A década dos trabalhadores: uma visão histórica dos novos desafios e da 
força política do sindicalismo brasileiro. Jornal do Brasil, p. 27, 27 jun. 1992.

\section{Como referenciar este artigo}

GAMA, Z. J. Cursos de formação de profissionais de educação mal avaliados e impactos no desempenho estudantil em testes de larga escala. Revista Ibero-Americana de Estudos em Educação, Araraquara, v. 16, n. 4, p. 2427-2442, out./dez. 2021. e-ISSN: 1982-5587. DOI: https://doi.org/10.21723/riaee.v16i4.13844

Submetido em: $26 / 07 / 2021$

Revisões requeridas em: 24/08/2021

Aprovado em: 20/09/2021

Publicado em: 21/10/2021 